\title{
Insulin Antibodies: Description of specific serum protein localization in a patient with insulin resistant diabetes
}

\author{
E. Crrast, O. Hogeman, R. Luft, J. Porath and A. Roovete
}

From the Department of Endocrinology and Metabolism, Karolinska Sjukhuset, Stockholm; the Department of Medicine, Centrallasarettet, Falun and the Department of Biochemistry, University of Uppsala, Uppsala, Sweden

Eingegangen am 16. November 1965

Summary. 1. A patient with insulin resistant diabetes mellitus has been described in detail with emphasis upon the time relationship between prior insulin therapy for mental illness and the subsequent development of overt diabetes. 2. The localization of the insulin antibodies in the $\gamma_{\mathrm{G}}$-globulins with some extension into the region of $\gamma_{\mathrm{A}}$ has been delineated. 3 . The possible relationship between the immunologic responsiveness of the patient and the eventual manifestation of the disease is discussed.

Anticorps anti-insuline: Localisation d'une protéine spécifique du sérum chez une malade avec diabète insulinorésistant.

Résumé. 1. Un cas de diabète insulino-résistant est présenté en détail et l'attention attirée sur le rapport chronologique entre le début du diabète et une série de traitements antérieurs à l'insulino-choc. 2. Les anticorps anti-insuline ont été localisés dans les $\gamma$-globulines par l'emploi consécutif d'électrophorèse et de filtration sur Sephadex. La majorité des anticorps anti-insuline s'est révélée être des globulines $\gamma_{G}$, avec un débordement important sur la région des globulines $\gamma_{A}$. 3. La relation pathogénique possible entre la réaction immunologique de la malade et la manifestation du diabète est considérée.

Insulin-Antikörper: Beschreibung der Lokalisation eines spezifischen Sernm-Proteins bei einem Patienten mit insulinresistentem Diabetes.

Zusammenfassung. 1. Ein Fall von insulinresistentem Diabetes mellitus bei einer Patientin wird ausführlich beschrieben. Das Verhältnis zwischen einer früheren Insulinbehandlung aus psychiatrischer Indikation und dem späterem Auftreten von manifestem Diabetes wird besonders berücksichtigt. 2. Die Lokalisierung der Insulinantikörper in der $\gamma_{G}$-Globulinfraktion mit Übergang auf die $\gamma_{A}$ Fraktion wird beschrieben. 3. Der mögliche Zusammenhang zwischen der Immunisierung der Patientin und dem Manifestwerden der Krankheit wird diskutiert.
The antigenicity of insulin is well established. Antibodies are formed by administration of heterologous as well as homologous insulin to animals. Insulin is a weak antigen, which is demonstrated by the fact that the majority of diabetic patients do not lose their insulin sensitivity despite several years of treatment with heterologous insulin. On the other hand, it has been pointed out that all diabetics develop measurable titers of antibodies when insulin has been given for at least three months (BERson et al., 1956).

Table 1. Percentage of ${ }^{131} I$-insulin activity migrating with protein fraction VI (see Fig. 9)

\begin{tabular}{clc}
\hline & \multicolumn{2}{l}{ Percentage of ${ }^{131}$ I-insulin activity } \\
\cline { 2 - 2 } tube no.g & $\begin{array}{l}\text { at appli- } \\
\text { cation site }\end{array}$ & $\begin{array}{l}\text { migrating } \\
\text { with protein }\end{array}$ \\
\hline 20 & 92.9 & 7.1 \\
36 & 92.6 & 7.4 \\
40 & 92.1 & 7.9 \\
44 & 88.6 & 11.4 \\
48 & 85.9 & 14.1 \\
56 & 79.3 & 20.7 \\
61 & 75.7 & 24.3 \\
66 & 71.5 & 28.5 \\
72 & 68.8 & 31.2 \\
78 & 68.1 & 31.9 \\
83 & 76.4 & 23.7 \\
86 & 80.8 & 19.2 \\
92 & 89.3 & 10.7 \\
100 & 90.5 & 9.5 \\
108 & 92.8 & 7.2 \\
134 & 93.7 & 6.3
\end{tabular}

A large number of instances of diabetes mellitus with insulin resistance has been reported in literature. In several of these, high titers of insulin binding antibodies have been demonstrated. It is not known why only a few diabetic patients develop such a hyperergic reaction towards the insulin given. Reviews of the pertinent literature in this field were recently made by DeCKert (1964) and by ShIPP et al. (1965).

It is the purpose of this report to describe in detail a patient with diabetes mellitus with insulin resistance in whom the first steps towards a precise description of the localization of insulin antibodies in serum protein have been accomplished.

\section{Patient description}

B. Ö./1964. A 62 years old married woman was referred to us in 1964 because of diabetes mellitus requiring unusually large doses of insulin.

There was a family history of diabetes: a maternal uncle, all four children of a maternal aunt, and a child of one of these cousins had diabetes.

The patient had been operated on for non-toxic goitre in 1935, and had been treated for pyelonephritis in 1927 after childbirth. Since 1923 she had been under care for anxiety neurosis and psychosis on several occasions. She had in 1927 given birth to one child.

In 1950, in connection with a period of anxiety, the patient was given a series of insulin shocks. The insulin 
used was presumably a combination of beef and pork insulin. It induced severe hypoglycemia but no allergic manifestations. In 1952 she was examined because of polydipsia and polyuria of rapid onset, and it was found that she had diabetes mellitus with a fasting blood sugar of $300-350 \mathrm{mg}$ per $100 \mathrm{ml}$, and an excretion of $60-70 \mathrm{~g}$ of sugar per day. From the very beginning it was impossible to treat the patient's diabetes successfully with pork-beef insulin. Partly because the patient seemed to be resistant even to large doses of insulin, and partly because of a reaction at the site of insulin injection consisting of local edema, rash and itching, appearing already at the first injection. Following intravenous administration of insulin she developed nausea, general malaise and fever. The same kind of side-effects were also given by beef-pork insulin that had been recrystallized several times.

The attempts to treat the patient's diabetes with insulin were given up, and up to 1956 she was only on a low-carbohydrate diet, excreting about $60 \mathrm{~g}$ of glucose per day but without ketonuria. BZ 55 (sulphanilylbutyl-carbamide) was tried without effect.

In $195 \%$, in connection with an upper respiratory infection, the patient went into a precomatous state with metabolic acidosis. This time insulin intravenously, in doses up to 2000 units per day, was not followed by any unfavorable reaction but was without effect on blood sugar and ketonemia. Prednisolone, $20 \mathrm{mg}$ daily for some days, brought about some sensitivity to the same insulin, to which the patient had earlier been resistant, and now 200 units of regular insulin could correct the acidosis. Since then the patient has been for most of the time on 200 units of regular insulin per day, divided into three doses, but without corticoid hormones. No acidosis has appeared during these latter years, but she has regularly excreted 50$60 \mathrm{~g}$ of sugar.

Diabetic retinopathy was noticed in 1959 but has since shown no progression. There has been no albuminuria and no signs of neuropathy.

Examination in 1964: Elderly woman, in good general condition: body weight $83 \mathrm{~kg}$, height $166 \mathrm{~cm}$; increased pigmentation on the lower parts of the legs with oedema and induration; somewhat lipodystrophic facies; normal secondary sex characteristics; no signs of circulatory failure; on the back and chest numerous spider naevi; no palmar erythema, no icterus, no obvious signs of portal hypertension; moderate nonintentional tremor of both hands but no other signs of Parkinsonism; the thyroid gland was diffusely enlarged and contained an adenoma with a diameter of about $2 \mathrm{~cm}$; blood pressure $190 / 100 \mathrm{~mm} \mathrm{Hg}$; no abnormal physical findings from the heart and peripheral vessels; the liver was palpated one $\mathrm{cm}$ below the rib margin, and the edge was somewhat firmer than normal; and neurological examination gave normal findings.

General laboratory findings in 1964: Hemoglobin $14.2 \mathrm{~g}$ per cent; RBC, WBC and differential counts normal; electrolytes in plasma normal; sedimentation rate $50 \mathrm{~mm} / 1 \mathrm{hr} ; \mathrm{B}_{12}$ in serum $290 \mu \mathrm{g}$ per $\mathrm{ml}$; serum iron $98 \mu \mathrm{g}$ per $100 \mathrm{ml}$; cholesterol $226 \mathrm{mg}$ and phospholipids $279 \mathrm{mg}$ per $100 \mathrm{ml}$; triglycerides $106 \mathrm{mmol}$ per 1; no albuminuria; urinary sediment normal; and normal capacity to concentrate the urine. Excretion of 17-ketosteroids and 17-ketogenic steroids and free catechol amines was normal. Thyroid biopsy showed cystic degeneration of an adenoma. Electrocardiograms demonstrated coronary insufficiency.

Antibodies to thyroglobulin were present in a concentration of 1:800; there were no other thyroid antibodies. No LE cells could be demonstrated. The Wassermann reaction and direct Coomb's test were negative. Cold agglutinins were absent and hemagglutination test for rheumatoid arthritis was positive in dilution $1: 128$.

Bilirubin was $0.9 \mathrm{mg}$ per $100 \mathrm{ml}$, transaminase values (GOT, GPT) were moderately increased ( 86 and 65 units, respectively), and plasma protein electrophoresis showed relatively low albumin $(49 \%)$ and elevated gamma globulin concentrations $(33 \%)$. Total protein in plasma was $9.1 \mathrm{~g}$ per $100 \mathrm{ml}$. Liver biopsy demonstrated portal cirrhosis of moderate degree.

Roentgenograms of the kidneys, oesophagus, peripheral arteries, heart, lungs and colon were normal. Cholecystogram failed to fill the gallbladder.

Diabetic state in 1964: While on $1750 \mathrm{kcal}$ and $175 \mathrm{~g}$ of carbohydrates and 200 units of regular insulin per day the patient had no ketonuria but excreted $20-80 \mathrm{~g}$ of glucose per 24 hours. Fasting blood sugar varied between $100-270 \mathrm{mg}$, and postprandial blood sugar between $250-390 \mathrm{mg}$ per $100 \mathrm{ml}$. When insulin administration was gradually decreased and then stopped, blood sugar increased slowly but never exceeded $400 \mathrm{mg}$ per $100 \mathrm{ml}$. After two days without insulin glycosuria went up to $250 \mathrm{~g}$ per day, and ketonuria appeared. When the insulin was raised to 450 units, fasting blood sugar decreased to $60 \mathrm{mg}$ per $100 \mathrm{ml}$, the glycusuria disappeared, and the patient had attacks of hypoglycemia.

The eye grounds bilaterally showed microaneurysms, exudates and hemorrhages but no proliferative changes. Vision was almost normal in both eyes after correction. Deep pain perception of the feet was moderately decreased.

\section{Methods}

Blood glucose was determined with a commercial glucose oxidase reagent (Kabi Reagent, Sweden). Glucose in urine was measured polarimetrically.

Preparation of labelled insulin. Insulin was labelled with 131-iodine by the method of BRUNFELDT and DeскеRт (1964a). In order to raise the specific activity the amount of insulin to be labelled was markedly diminished in relation to the isotope. By using $0.017 \mathrm{mg}$ of insulin and $10 \mathrm{mC}$ of 131 -iodine the specific activity obtained is about $30-40 \mathrm{mC}$ per $\mathrm{mg}$. No damage to the labelled insulin could be detected on paper chromat- 
ography (see Fig. $3 \mathrm{~A}$ ). The purity of the labelled insulin preparations used throughout the study was checked.

Insulin antibodies in plasma. The presence of insulin antibodies was demonstrated by incubating for four days at $4^{\circ} \mathrm{C} 0.2 \mathrm{ml}$ of plasma with $0.2 \mathrm{ml}$ of a solution of labelled insulin containing $2000 \mu$ units per ml. Of this mixture, $50 \mu \mathrm{l}$ was applied to strips of electrophoresis paper (Carl Schleicher \& Schüll, no. 2043 B). The electrophoresis was performed on an LKB $3276 \mathrm{~B}$ Paper Electrophoresis Apparatus, using barbiturate buffer with an ionic strength of 0.125 and $\mathrm{pH}$ of 8.6. Three $\mathrm{mA}$ per strip was applied for 4 hours. Measurements of activity along the strip were made with a Baird-Atomic Chromotography Scanner behind a narrow slot.

It was not considered important for the present study to measure the titer of insulin antibodies in the patient's plasma. For a rough estimation of these antibodies, insulin binding capacity was measured in serially diluted plasma with the technique mentioned above. In addition, increasing amounts of insulin were added to undiluted plasma, and the distribution of the radioactivity between antibody-bound and free insulin examined.

In order to compare the affinity of the patient's antibodies for porcine and human insulin respectively, plasma diluted 1:32 was incubated with a mixture of $2000 \mu$ units of labelled porcine insulin and $2000 \mu$ units of unlabelled porcine or human insulin. The degree of displacement of radioactivity from the globulin region induced by unlabelled insulin was measured. The porcine insulin used contained 30 units and the human insulin 24 units per $\mathrm{mg}$.

Fractionation of plasma. This was performed by zone electrophoresis and by gel filtration on Sephadex.

Zone electrophoresis. The electrophoretical fractionation was achieved by employing the large column designed by Porath (1964). It consists essentially of an internally and externally cooled annular column with connections made with the electrode compartments in such a way that the buffer outside the separation chamber can be continuously mixed without disturbing the protein-containing liquid.

A $68 \mathrm{~cm}$ high column of water-pyridine extracted cellulose powder (Munktell Cellulose Powder, Grycksbo Pappersbruk, Sweden) was packed and washed with sodium diethylbarbiturate buffer of $\mathrm{pH} 8.6$, containing $0.02 \%$ sodium azide to prevent bacterial growth.

$115 \mathrm{ml}$ fresh serum was filtered into the column. When the upper edge of the zone had reached a position about $5 \mathrm{~cm}$ below the surface the flow was stopped. The electrode chambers and connecting tubes were filled with the diethylbarbiturate buffer, and a potential difference of $350 \mathrm{~V}$ was applied across the electrodes. The current was $470 \mathrm{~mA}$. After 89 hours electrophoresis time the fractionation was stopped. The plasma proteins were displaced from the disconnected column. After sampling in a refrigerated collector the absorbancy at $284 \mathrm{~m} \mu$ was measured. The samples were pooled in 7 fractions as indicated in Fig. 7, and concentrated in dialysis tubings subjected to external evacuation ("negative pressure dialysis").

Molecular sieving on Sephadex. Gel filtration was performed in a column containing Sephadex G 200 in $0.5 \mathrm{M}$ Tris- $\mathrm{HCl}$ buffer of $\mathrm{pH} 8.2$ with $0.002 \mathrm{M}$ disodium ethylene diamine tetraacetate. A detailed description of the column design and the general procedure has been given elsewhere (Porath and BENNICH, 1962). The dimensions of the column used in this study were $104 \times 7 \mathrm{~cm}$. Samples of $50-60 \mathrm{ml}$ were applied to the column. Elution was performed at a rate of $60-70 \mathrm{ml}$ per hour, 15-16 $\mathrm{ml}$ fractions were collected, and their absorbancy at $280 \mathrm{~m} \mu$ measured.

The disappearance rate of intravenously administered labelled insulin. After previous blocking of the thyroid with sodium iodide, the patient was given $40 \mu \mathrm{C}$ of ${ }^{131}$ I-insulin intravenously. Venous blood samples were drawn at 5 minutes intervals for the first half hour, then every 10 minutes for 30 minutes, and every 20 minutes for the second hour. The plasma proteins were precipitated with an equal volume of $10 \%$ trichloracetic acid (TCA). The radioactivity of the TCA precipitates after washing with TCA was determined in the Packard Auto-Gamma Spectrometer. The TCA precipitate will include free labelled insulin, labelled insulin bound to antibodies, and degradation products of labelled insulin bound to plasma proteins. No attempt was made to measure specifically the radioactivity due to labelled insulin per se.

\section{Results}

Effect of insulin intravenously. As seen in Fig. 1, as large a dose as 30 units of beef-pork insulin had only slight immediate effect on the blood sugar. There was a

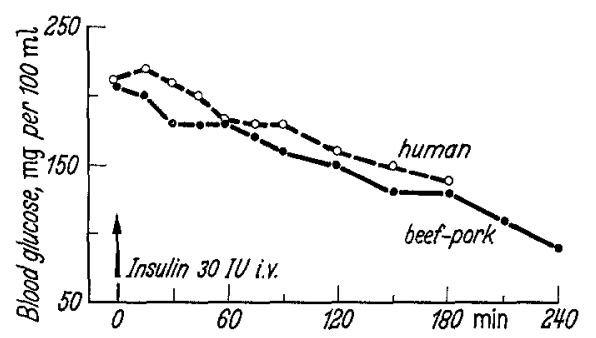

Fig. 1. Effect of 30 I. U. of beef-pork and human insulins on blood glucose level. Insulin was injected intravenously at time zero. Open circles, blood glucose after human insulin; filled circles, after beef-pork insulin

retarded fall of blood sugar, and not until 3 hours after the injection had a normal or almost normal blood sugar been reached. Similar results were obtained when 30 units of human insulin were injected intravenously, showing that the resistance comprised also human insulin.

Tolbutamide, $1 \mathrm{~g}$ intravenously, had no effect on blood sugar for the 3 hours during which this was measured. 
The disappearance rate of "labelled insulin" after intravenous injection is shown in Fig. 2. For comparison the mean curve of disappearance of TCA-

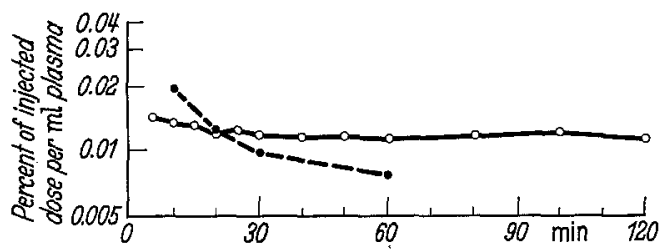

Fig. 2. Disappearance rate of labelled insulin. $0.4 \mathrm{mC}$ of ${ }^{131} \mathrm{I}$-insulin was injected intravenously at time zero. Open circles, radioactivity (percentage of total dose given) in TCA-precipitate of $1 \mathrm{mI}$ plasma from present patient. Filled circles, disappearance rate of injected labelled insulin in untreated diabetic patients, as measured by Bolinger et al. (1964)
In order to estimate approximately the amount of insulin antibodies a series of dilutions of the patient's plasma was incubated with labelled insulin, and the distribution of radioactivity was determined as mentioned above. As seen in Fig. 4, the first indication of a peak at the application line appeared in the plasma dilution $1: 8$. The ratio $1: 1$ between this peak and the one in the $\beta$ - $\gamma$-region was reached in the dilution $1: 64$. Not until the dilution $1: 256$ did the radioactivity in the $\beta$ - $\gamma$-fraction tend to disappear.

Fig. 5 demonstrates that the patient's plasma was able to bind almost all the labelled insulin up to 600000 $\mu$ units per $\mathrm{ml}$.

precipitable radioactivity in a group of untreated diabetics reported by Bolinger et al. (1964) is also included. The disappearance rate of the radioactivity was greatly diminished in our patient.

Insulin antibodies in plasma. Fig. 3 demonstrates the distribution on the electrophoretogram of labelled insulin incubated with plasma from a healthy subject and from the patient. In normal plasma the insulin remained at the origin indicating that no other component was competing with the affinity of the paper for insulin. In

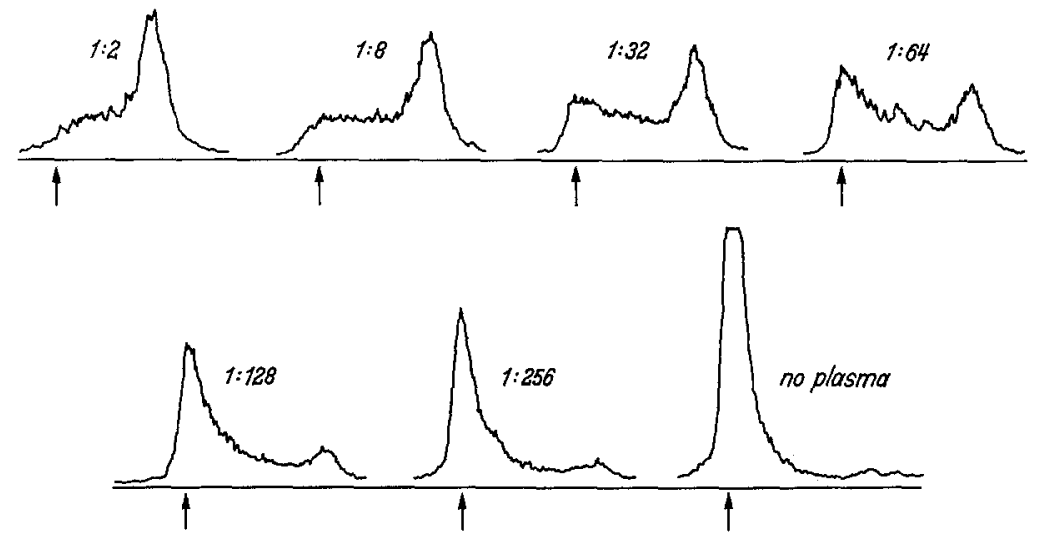

Fig. 4. Distribution of radioactivity in electrophoretogram of plasma dilutions (1:2 to $1: 256$ ) incubated with labelled insulin. Arrow indicates point of application of plasma

the patient's plasma all of the labelled insulin migrated with the protein fractions. Almost all of the radioactivity corresponded to the $\beta$ - $\gamma$-globulin fractions.
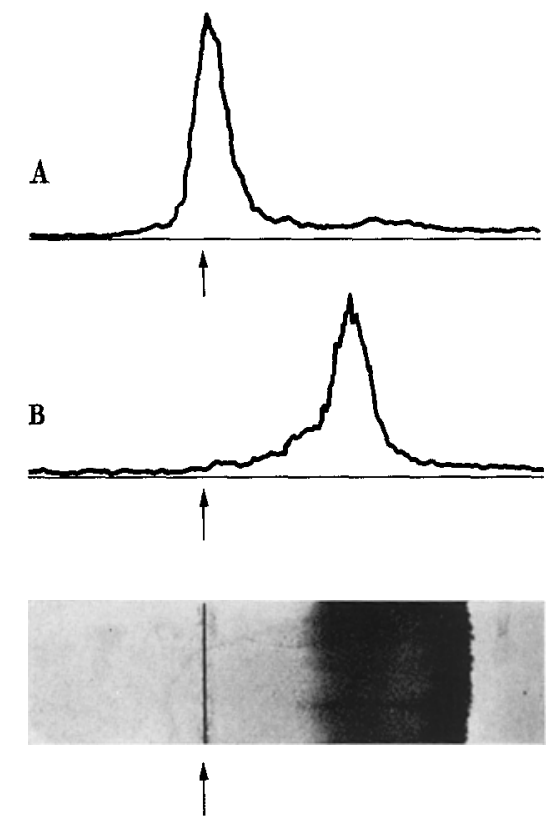

Fig. 3. Distribution of radioactivity in electrophoretogram of plasma incubated with labelled insulin. $A$, plasma from healthy subject, $B$. patient's plasma. Arrow indicates point of application of plasma
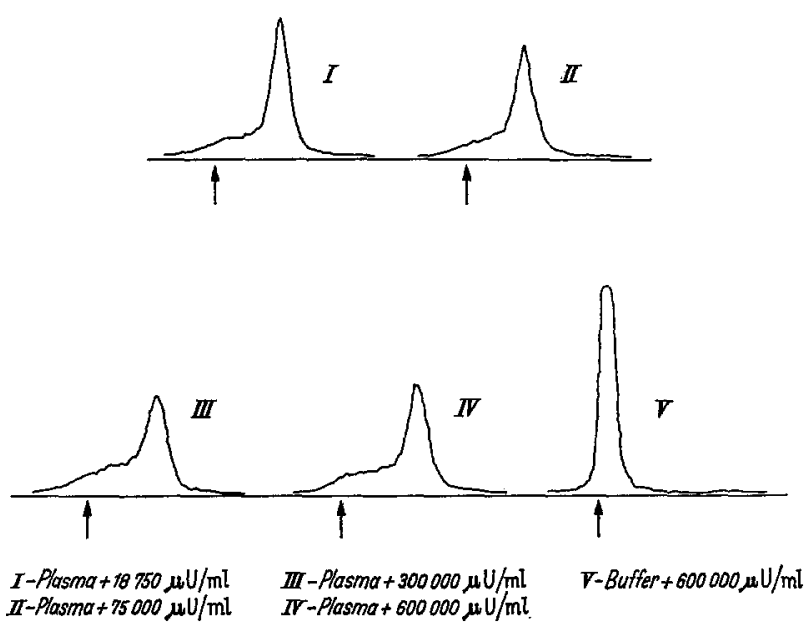

Fig. 5. Insulin binding capacity of plasma. Labelled insulin and increasing amounts of unlabelled porcine insulin (18750 to 600000 units per ml) were incubated with patient's plasma. Scanning of electrophoretogram. Arrow indicates point of application of plasma

The affinity of the insulin antibodies for porcine and human insulin seemed to be of equal magnitude, since both insulins induced the same degree of displacement of radioactivity from the globulin region (Fig. 6).

Fractionation of plasma for localization of insulin antibodies. By zone electrophoretic separation of 


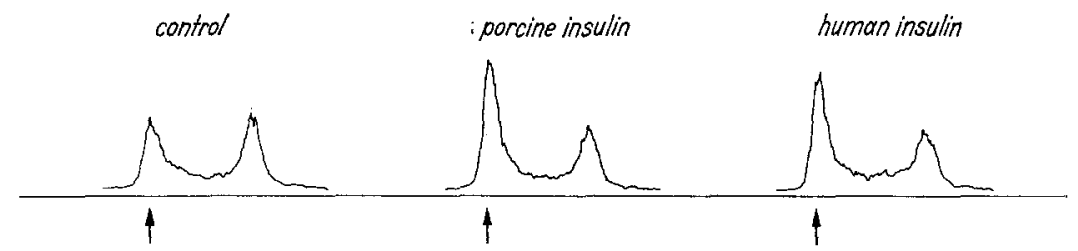

Fig. 6. Binding of porcine and human insulin by patient's plasma diluted 1:32. Equal amounts of labelled and unlabelled insulin were incubated with plasma. $A$. human insulin, $B$. porcine insulin. Arrow indicates point of application of plasma

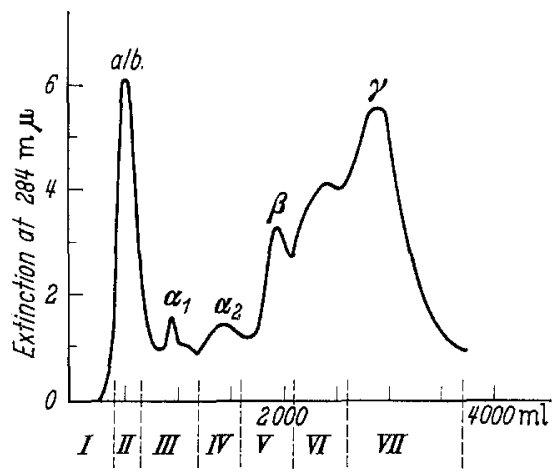

Fig. 7. Fractionation of patient's plasma by zone electrophoresis. Protein distribution of eluate on abscissa, adsorbancy at $284 \mathrm{~m} u$ on ordinate. Roman numbers I-VII refer to collected fractions (prealbumin to $\gamma$-globulin)

plasma proteins seven fractions were collected (Fig. 7) and studied for insulin-binding capacity. As seen in Fig. 8, the prealbumin (I), albumin (II), $\alpha_{1}$ (III) and $\alpha_{2}$ (IV) fractions did not bind labelled insulin. The binding capacity increased abruptly in fraction $V$ corresponding to $\beta$-globulins, and marked binding was present in all three fractions corresponding to the $\beta$ - $\gamma$-globulins. The most pronounced binding occurred in the inter- $\beta$ - $\gamma$-region (fraction VI).

In order to localize more definitely the protein fraction that was binding insulin each of the electrophoretic fractions $V$-VII was passed through a Sephadex G 200 column. Fig. 9 demonstrates the protein distribution of fraction VI (inter- $\beta$ - $\gamma$-globulins). The collecting tubes denoted in Fig. 9 were analyzed. for insulin-binding capacity. The radioelectrophoretograms after scanning were cut into two parts, one containing the activity at the application site and the other the migrating activity. The activity of each part was measured in a well counter (Packard AutoGamma Spectrometer). The percentage of activity migrating with proteins is given in Table 1.

It can be seen from Table 1 and Fig. 9 that the change in insulinbinding capacity did not follow the protein pattern. Most of the activity was concentrated in the region of $\gamma_{G}$ globulins with some extension into the region of $\gamma_{A}$. Similar results were obtained when fractions $V$ and VII ( $\beta$ - and $\gamma$-globulin fractions) were submitted to the same procedure as fraction VI.

\section{Discussion}

The detailed knowledge of the chemistry of insulin makes the insulin-antiinsulin systems attractive

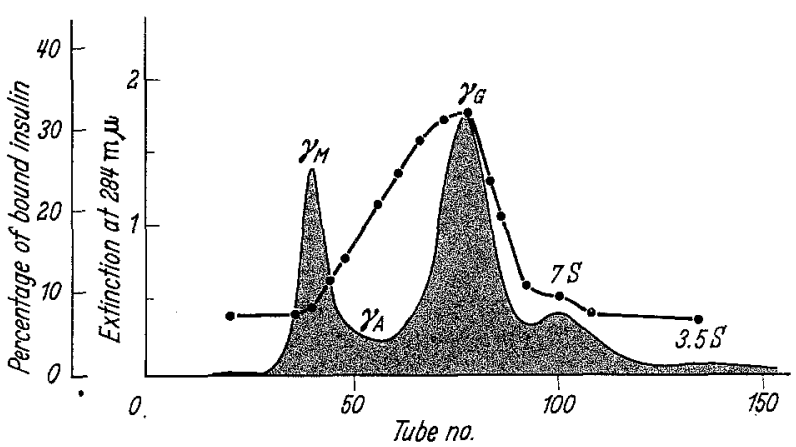

Fig. 9. Distribution of insulin binding capacity within the proteins of fraction VI. Shadowed area denotes protein distribution of fraction VI after molecular sieving on Sephadex G200. Filled circles denote insulin-binding capacity of eluate in per cent of total radioactivity of incubated insulin models for the study of the specific chemical interaction between protein antigens and the corresponding antibodies. Recently, YAGI et al. (1965) have reported that the B-chain of insulin is the main carrier of the antigenic determinants for the antibody production in guinea pigs, while the hormonal activity requires that the A- and B-chains be properly linked through disulfide bridges. In order to understand the immunochemistry of insulin more information is needed concerning the nature of the antiinsulins.

Insulin antibodies in human plasma have previously been localized in $\beta_{2 \mathrm{~A}}$ globulin (BERsoN and YALOW, 1957), in $\gamma$-globulin (SCHoN et al., 1955; Morse and Heremans, 1962) and in both $\beta$ - and $\gamma$-globulins (Mrller and Ower, 1960). Using consecutively 
immunoelectrophoresis and DEAE cellulose chromatography, YAGI et al. (1963) were able to localize the insulin antibodies in the $\gamma_{1}$-and $\gamma_{2}$-globulins. Recently, SAMOLS and JoNES (1965) described the occurrence of three types of insulin antibodies in insulin-treated patients: insulin binding, passive cutaneous anaphylaxis and hemagglutinating antibodies. The activity of the last antibody in recently treated patients was located to the $\mathrm{I}_{\mathrm{gM}}$-globulin, whereas insulin binding activity was found in the $7 \mathrm{~S} \gamma$-globulins. In chronically treated patients, all three types of antibodies were found in the 7S $\gamma$-globulin fraction. The distribution of insulin binding capacity among the fractions obtained by sequential application of zone electrophoresis and molecular sieving from the patient's plasma, shows that this activity is not associated with macroglobulins. Instead, the antibody activity is located in the gel filtration diagram where the $\gamma$-globulins are found to have sedimentation coefficients around $7 \mathrm{~S}$. The broad distributions indicate heterogeneity, although most of the antiinsulin is located in a region between that of $\gamma_{G}$ - and $\gamma_{A}$-globulin. Antiinsulin may therefore belong to one, both or neither of these two groups of $\gamma$ globulins. The choice among these possibilities cannot be made until the antiinsulin has been more precisely characterized immunologically or chemically. Thus at the present stage we can state with certainty only that the distribution of antiinsulin, both after electrophoresis and gel filtration, exhibits the interesting feature of an abscence of concordance between its distribution and that of the known classes of $\gamma$ globulins.

The cause of the occurrence of insulin antibodies and, thus, of the insulin resistance of the patient is of some speculative interest. Insulin resistance has usually been reported in diabetic patients treated successfully with insulin for a short period or for some length of time. Our patient, when she did not have clinical evidence of diabetes mellitus, reacted normally to insulin given for a short period as psychiatric treatment. Not until two years later did she show overt signs of diabetes, and then, at the very first attempt to treat her diabetes, the insulin resistance became apparent. The first injection of insulin given at this time resulted in local tissue changes indicating the presence of some type of tissue-bound antibody. Thus, the patient had developed high titers of antibody to insulin after only a short series of insulin injections given two years previous to the onset of diabetes.

It is tempting to visualize a possible connection between the insulin antibodies and the development of diabetes mellitus. However, it is then difficult to explain the time lag of two years between the initial challenge of the patient with exogenous insulin and the appearance of diabetes. Furthermore, it has been shown that animals immunized even with homologous insulin do not develop diabetes despite the fact that their serum, when injected into healthy animals, gives rise to hyperglycemia (BRUNFELDT and DeCKERT, 1964b; Rexold et al., 1964). This resistance of the experimental animals to circulating insulin antibodies could be explained by an adaptation of the islet cells to the successively increasing demands for insulin during the immunization period. Recent findings by GRoDSKX (1965) speak in favor of such a hypothesis. He has been able to demonstrate that circulating antibodies to bovine insulin in diabetic patients carried large amounts of endogenous insulin. The present patient with her pronounced family history of diabetes might have been lacking this capacity to cope with an increasing demand for insulin, the latter in turn being due to the formation of insulin antibodies. In a previous publication we have shown that both diabetic patients and a number of subjects with a normal glucose tolerance (prediabetics?) have a reduced capacity to increase plasma insulin following glucose infusion (Cerasi and Luft, 1963). The time period between immunization and appearance of diabetes might then be an expression of the time needed for the exhaustion of the $\beta$-cells of the pancreas in such a susceptible individual.

Acknowledgements. The authors wish to express their gratitude to Dr. H.C. HAgrdorn, Nordisk Insulinlaboratorium, Gentofte, Denmark, for the gift of highly purified porcine insulin; and to Dr. J. ScHLICHTKRULL, Novo Industri A/S, Copenhagen, Denmark, for the gift of highly purified human insulin.

This work was supported by grants from the Swedish Medical Research Council (Y 136/1964) and the Swedish Natural Science Research Council.

\section{References}

BERSON, S.A., and R.S. YALOW: Ethanol fractionation of plasma and electrophoretic identification of insulinbinding antibody. J. clin. Invest. 36, 642-647 (1957).

- - A. Bauman, M. A. Rothschuld and K. NewerLy: Insulin-131I metabolism in human subjects: Demonstration of insulin-binding globulin in the circulation of insulin treated subjects. J. clin. Invest. 35, 170-190 (1956).

Bolmger, R.E., J.H. Morris, F.G. MoKnight and D. A. DIEDERICH: Disappearance of $\mathrm{I}^{131}$-labelled insulin from plasma as a guide to management of diabetes. New Engl. J. Med. 270, $767-770$ (1964).

BRUnfeldT, $K$, and T. Deckerr: The antigenic properties of pig insulin. Acta endocr. (Kbh.) 47, 353-366 $(1964 a)$.

- - Antibodies in the pig against pig insulin. Acta endocr. (Kbh.) 47, 367-370 (1964b).

Cerrasi, E., and R. LuFt: Plasma-insulin response to sustained hyperglycaemia induced by glucose infusion in human subjects. Lancet 1963 II, $1359-1361$.

Deckert, T.: Insulin antibodies. Copenhagen, Munksgaard, 1964.

GroDsky, G.M.: Production of autoantibodies to insulin in man and rabbits. Diabetes 14, 396-403 (1965).

Morse, J.H., and J.F. HEREmans: Immunoelectrophoretic analysis of human insulin-binding antibody and its papain-produced fragments. J. Lab. clin. Med. 59, $891-897$ (1962).

MILLER, H., and P. OwEN: Immunoelectrophoresis of insulin-binding antibodies. Nature (Lond.) 188, 67 $68(1960)$. 
Porath, J.: Column electrophoresis on a large scale. Science Tool 11, 21-27 (1964).

-, and H. Bennion: Arch. Biochem. Biophys., Suppl. 1, $152-156(1962)$.

Revold, A.E., J. Steinke and J. S. Soeldner : Immunologic studies with homologous and heterologous pancreatic insulin in the cow. Ciba Foundation Colloquia on Endocrinology. The Aetiology of Diabetes Mellitus and its Complications. London, J. \& A. Churchill, 1964.

SAmors, E., and V. Jones: Insulin resistance, and the relationship of human antibodies to insulin when measured by three different methods. First Annual Meeting of the European Association for the Study of Diabetes, 1965.

Schon, A.H., M. Kaye, E. McGarry and B. Rose: Localization of an insulin-neutralizing factor by zone electrophoresis in a serum of an insulin-resistant patient. J. Lab. clin. Med. 45, $765-770$ (1955).

Shipp, J.C., R.W. Cunningham, R.O. Russeti and A. MARBLE : Insulin resistance: clinical features, natural course and effects of adrenal steroid treatment. Medicine 44, 165-186 (1965).

Yagi, Y., P. Maier, D. Pressman, C.E. Arbesman, R.E. Retsman and A.R. Lenzer: Multiplicity of insulin binding antibodies in human sera. J. Immunol. 90, $760-769(1963)$.

- - - Antibodies against the component polypeptide chains of bovine insulin. Science 147, 617-619 (1965).

E. Cerast

Tjänste Karolinska Institutet

Endokrinologiska avdelningen

Stockholm 60/Sweden 